\title{
THE APPLICATION OF INNOVATIVE TEACHING TECHNIQUES AS A GOOD POLICY TO REDUCE THE ATTRITION RATE AT UNIVERSITY
}

Núm. 1 (2013), pp. 117-132

Lucía Inglada-Pérez ${ }^{1}$, Oliver Soto, Edmundo Tovar ${ }^{2}$,

Recibido: Junio, 2013

Aceptado: Septiembre, 2013

JEL Clasif: H39, I21, I23, Z18

\footnotetext{
${ }^{1}$ Hereditary Endocrine Cancer Group, Spanish National Cancer Research Centre (CNIO), Madrid, Spain linglada@cnio.es.

${ }^{2}$ Facultad de informática, Universidad Politécnica de Madrid, Campus de Montegancedo, Boadilla del Monte (Madrid, Spain).
} 


\begin{abstract}
In this paper we study how the application of new innovative teaching techniques in our school, has produced an overall improvement in the performance of students along the school years 2005-2008. Students with a worse previous level of student achievement in highschool have not only increased their performance but also the school attrition rate has lowered. Thus, we prove that policies focusing on improving student performance can be successful to increase in the long run the deficit of students.
\end{abstract}

Key Words: Learning strategies; Teaching methods; Educational evaluation; Engineering education. Innovative teaching.

\title{
Resumen
}

En el presente estudio se estudia el impacto de la aplicación de nuevas técnicas innovativas en la educación de los estudiantes de la Universidad Politécnica de Madrid durante los años 2005--2008. Los resultados son muy esperanzadores. No sólo se ha conseguido una mejora en el rendimiento de los alumnos sino que la tasa de suspensos haya disminuido considerablemente. La práctica que se propone constituye una buena opción para incrementar el déficit de alumnos y mejorar el rendimiento de los mismos.

Palabras Clave: Estrategia de enseñanza; métodos enseñanza; ingeniería; innovación; métodos de aprendizaje. 


\section{Introduction.}

In recent years there has been a sharp decline trend of enrollment in Computer Engineering studies - in particular in our school (Universidad Politécnica de Madrid, UPM) and in general in all the country, probably due, to the fact that the supply has been diversified and intensified, increasing the number of competing schools offering a degree in Computer Engineer. This new scenario has drastically reduced the number of students who enrolled in our studies, as well as lowered the requirements to access our school. Therefore there has been a decline in the quality of the pool of students and an increasement of early school dropout rate.

This shortage of students is common to many Engineering schools around the world and therefore attracting new students has become an important issue for politicians [Becker 2010; Winckler 2006]. The development of innovative teaching techniques (ITT) might be a solution. In fact, several researchers have studied the benefits of applying an active learning environment versus a passive lecture model [Bonwell 1991, $\mathrm{Hu}$ 2008]. These new techniques have been proved to be more effective and therefore to produce a better outcome in students. Moreover Bonwell et al. state that these techniques improve "students" thinking and writing" [Bonwell 1991].

Alarmed by the high attrition rates of freshmen and amazed by an eventual recovery the last years, we have studied the academic outcome of the students of our school in order to detect if there is any factor that could explain why the last cohorts have outperformed previous cohorts which were theoretically better students as their grades in high school reflected. We discovered that during the last three years there have been many individual initiatives to develop innovative teaching techniques (ITT) that gathered in broader innovation groups that have put together professors from different subjects.

The rest of the paper is organized as follows; first we describe the environment of our school, how teaching was undertaken and how it has changed (section 2). A description of the research methodology is provided in section 3. Section 4 provides the results. Finally, the last two sections consist of a discussion of the results and a conclusion with a set of lessons learned from our study. 


\section{Context of our research: Computer Science education in our school}

\section{Teaching performed within the framework of the former study programs}

The former study programs did not have any provision of how classes had to be taught neither had they any hints to the professor of the competences they had to cover. Every department and subject coordinator fixed the minima contents to be covered in every subject. However, professors, sheltered by the constitutional right of academic freedom, could impose their own criteria and it was up to the subject coordinator to institute any kind of coordination regarding the knowledge transmitted, the ways it was done and, especially, how it would be evaluated.

Given that professors were not required to comply with any formation to start teaching, nearly all the lessons followed the classical pattern of explanatory classes. In this scheme, there is little room to student participation or any form of active learning. Regarding evaluation, students were mainly graded based on their performance in a single test. Some professors incorporated projects to be completed by the students or groups of students. Most of the work was done off the class and there was no balance with the workload carried at class, and there was no care about the total workload.

\section{Teaching innovation: a definition}

We will consider teaching innovation as the experiences developed in order to make students a more active part of the learning process and the incorporation of new technologies in the learning process. The following initiatives were undertaken in our school:

- Creation of web based compilation of resources to improve the autonomous learning of the student and to enlarge the repository at hand for professors.

- Creation of web platforms like chats and forums to interchange knowledge and to share difficulties found. 
The Application of innovative teaching techniques as a good policy to reduce the attrition rate at University

- Decrease in the theoretical explanation and a consequent increase in practical explanations and supervised resolutions of problems by the students.

- Creation of teams of students to resolve the problems.

- Application of continuous evaluation based on problem solving and partial exams.

- Coordination with other subjects to solidify the learning.

- Development of communication skills, teamwork and cooperative learning.

- Development of the assessment of skills and competences along with knowledge.

- Application of alternative methods of evaluation as peer correction.

\section{Changes in the school: projects to implement innovative teaching techniques}

During the school year 2005-06 the University Rector started a program to fund professors who were innovating in the field of education. The basic idea was to establish solid teams that institutionalized the before disperse individual initiatives to improve student learning through new teaching techniques. They were developed in three main phases:

I. Timid start: in 2006 the first professors started their own innovative projects. These initiatives were from individual professors and they were not compulsory for the whole subject, and comprised mainly subjects related to Mathematics. There were extensive collaborations that stayed over time. In fact, once a project is over, its materials and experienced were in use in successive years.

II. Stabilization and conformation of groups: once the experiences proved to be successful, the following years they were applied more systematically and new groups were created. Some groups were based in a single subject, whereas others gathered professors from two or more subjects in order to coordinate their efforts. 
III. Institutional leadership: A coordination scheme was created to help professors to apply innovative teaching techniques, to put in common previous experiences already taken into practice in their own groups and to provide resources to implement new techniques for newcomers ${ }^{3}$.

\section{Methodology.}

\section{Data sources.}

Data on freshmen for a total of eight different cohorts was collected. We gathered the high school grades to access the University, age, the results obtained in all the subjects in the first year in June and September4 and other contextual variables like number of students per class and the presence of teaching innovation. All the data was obtained from the centralized system of the University, as registered by the official records.

\section{The explanatory model.}

For this purpose we have selected the cohorts from 2000-01 to 2007-08 as they are the ones for which we have more reliable data. From 2000 on we have standardized records for all cohorts. Thus the main difference among cohorts is the exposure to innovative teaching techniques.

We have developed the following model to test that the implementation of new innovative teaching techniques explains the improvement of the results of our students in the last years, once we have controlled by other impinging or confounders factors:

$$
\text { Rdto }_{i}=\alpha+\beta_{1} N P_{i}+\beta_{2} \operatorname{Yrs}_{i}+\beta_{3} \text { AvClass }_{i}+\beta_{4} T I_{i}+\varepsilon
$$

\footnotetext{
${ }^{3}$ More information about these groups can be retrieved here http://www.fi.upm.es/?pagina=591

4 In the Spanish university system students can do the same exam two times in a year in order to pass it.
} 
The Application of innovative teaching techniques as a good policy to reduce the attrition rate at University

Thus, the performance of a student $\mathrm{i}$ (Rdto) is a linear function of the previous level of student achievement (NP), the age in which she decided to start her studies (Yrs), the size of the class (AvClass) and the use of innovative teaching techniques (TI), being this one our focal variable. $\alpha$ is the intercept and $\varepsilon$ is the error term.

\section{Variable measurement.}

\section{Previous level of student achievement.}

This variable compounds both the result of the University exam (weighted a 40$50 \%)$ that is mandatory for accessing university and the student grades in high school (60\%). Although the grades range from o to 10, it is necessary to have a grade at least of 5 to access University.

Age.

Besides the normal access described above for most of our students, there is another access to University for students over 25 years.

\section{Size of the class.}

It is measured as the average of students per class in all subjects. As some students enroll in different courses with different teachers, we present the average of students with whom the student studied. Unfortunately, in older cohorts there was no record of the number of students per class, but per year. In these cases we have proceeded to average this number. In fact the actual numbers do not vary much from the average as students are allocated to have proportioned groups.

\section{Use of innovative teaching techniques (ITT).}

The first coordinated efforts started at 2005, but those have been more intense since 2006. This variable has been constructed as a dummy variable. It has been coded as a 1 the years when such efforts were made (cohorts 2005-2006, 2006-07 and 2007o8 and a o where there was no teaching innovation. 


\section{Measurement of performance.}

The performance (Rdto) of a student is calculated based on this formula:

$$
\operatorname{Rdto}_{i}=\frac{\sum_{j} 0.8^{c-1} * \text { Calif }_{i j} * C_{j} * 10}{\sum_{j} C_{j}}
$$

This metric takes into account the results in all subjects and the relative importance of every subject within the framework of the study plan. In the previous expression o.8c-1 is the attempt in which the student passed the subject $\mathrm{j}$; Califij is the highest numerical grade obtained by the student $i$ in the subject $j$, taking the value $o$ if the student did not make the exam; $\mathrm{Cj}$ is the number of credits 5 for subject $\mathrm{j}$ in the Curriculum. As a consequence, the student achievement, measured on a scale ranging from 0 to 100, is a function of the grades obtained in each of the subjects, weighted by the subject load work divided by the total amount of credits in which the student registered. We have used the highest numerical grade (ranging from o to 10) obtained by each freshman during a school year.

\section{Results.}

\section{Analysis of the cohorts.}

The number of students enrolled during the first years (2000-2004) was around 381 (range: 367-396). Afterwards there is a sharp decline in enrollment in our school, specially from 2003 (figure 1). In 2006 the number of students had declined dramatically, being less than a half than a few years ago. Moreover, the performance of each of the cohorts (the percentage of students that succeed in all the first year compulsory subjects) is very small, never surpassed the $12 \%$ (figure 2 ) and over a $17.6 \%$

\footnotetext{
${ }^{5}$ Those credits are counted accordingly with the European Credit Transfer System, which means that every credit is equivalent to 30 hours.
} 
The Application of innovative teaching techniques as a good policy to reduce the attrition rate at University

of the enrolled students have dropped our studies in the first year, without computing other students that complied with the minima criteria but decided to quit after the first year.

In table 1 we show the details of performance of each of the cohorts. According to their first year if they do not comply with the minima required to stay in our school, they cannot enroll again. If a student does comply with the minima but quits her studies, as they can be a returning student in the future and their record is still open, we cannot compute them as quitting their studies. Students do not close their academic folder unless they decide to transfer, which most of the cases does not happen. Thus, although uncertain, we can expect a bigger impact of the first year in low attrition data for future academic years.

\section{Analysis of the influence of innovative teaching techniques.}

All of the variables included in the model to analyze the effects of (ITT) were highly significant (table 2, p-value:<0,05) Our focal variable shows that those students who benefitted from these techniques display on average an improvement of 13 points (CI 95\%: 10-15) in a 100 scale.

Regarding the control variables, the previous level of the student is the most relevant one. A student improves her performance between 12.9 and 14.5 points per every extra point she obtained in access exams ${ }^{6}$. The age at which the student started learning in our school affects negatively its performance (o.3 points per year). Moreover, smaller classes tend to obtain better results, regardless of the fact that they are applying or not innovative teaching techniques. As expected, the lesser the number of students the better are the results. In fact the performance improves by 1 point per every 12 students reduction in the size of the class.

\footnotetext{
${ }^{6}$ We recall here that those exams are in a scale from o to 10, but admitted students have always grades between 5 and 10 .
} 


\section{Discussion.}

In this study we have shown that students who were part of groups where innovative teaching techniques and active learning processes were put in place have scored better results than their counterparts from previous years. In fact, if we take into account that the pool of students was not as good as the previous cohorts (table 1), we can say that the last cohorts have clearly outperformed previous ones whose potential was much bigger.

Several variables that can act as potential confounders have been included in the model in order to perform a good assessment. Other studies, along ours, have demonstrated that prior achievement is one of the best predictor of the future results of the students.

[Tyson 2011; Suresh, R. 2006; Kirby \& Sharpe, 2001; Takashira 1998; Thomas 1993] and that non strictly in room variables like the class size should be taken into account by policymakers as a potential explanatory variables when conceiving higher education planning [Takashira 1998],. Other studies have a larger time frame ([MollerWong, 1997; Felder 1998; Knight 2007, Bernold 2007]) but repeat the same approach in order to analyze if the student achievements are maintained in subsequent courses.

Benefits of ITT have been largely studied [Moller-Wong 1997; Mills 2003; Prince 2004;]. Moller-Wong et al [Moller-Wong, 1997] find a group of socio-demographic characteristics that indicate which groups might be at risk of dropping studies early and they classify students according to that risk. Others have observed the evolution of a group of students whom they applied innovative teaching techniques [Felder 1998]. They show that these students were not only more successful, but they indeed pursued graduate studies on the field in a larger proportion. All these studies point out the positive effect of innovative teaching techniques in one way or another. Thus, it can be noticed that higher education is not that far from primary and secondary school regarding prospects of performance.

The effectiveness of a teaching method cannot be measured solely in terms of results. In fact, some teaching techniques will not only lead to better results but some other intangible outputs like, for example, a better class climate and we know that those outputs cannot be measured. Moreover, our model allows us to establish a set of 
The Application of innovative teaching techniques as a good policy to reduce the attrition rate at University

expected outcomes for our students and therefore define some boundaries that represent higher or lower performance than expected and, that way, knowing if our students are deploying their full potential. That way, this system of detection of early deficiencies would be able to be connected with the recently created tutoring system.

It is not the aim of this study to provide a list of the best teaching techniques but offering more information to teachers to make decisions about their teaching techniques and provide the policy makers some keys about how to compose their groups, knowing in both cases the probable results of their decisions.

\section{Conclusion.}

Several lessons have to be learned from our experience. First, sometimes relatively good results can hide a structural problem, as it was the case in our school. Raw data can even hinder taking policy decisions if we do not look at them properly. Our school, the oldest in Spain, has had a tradition of high reputation and thus it has attracted very good students through time. University policy makers could content themselves with the raw results they were obtaining, not knowing that the higher results obtained were based more on the past prestige than the real performance of the school. When no more than $10 \%$ (even sometimes just 1\%) of students could meet all the requirements to pass exams as it was expected in the study plan, we can keep questioning the students' capacity (as some professors did), but we can also wonder if the real problem is the study plan and the way classes are taught.

Once the environment became more competitive with new schools offering grades in Computer Engineering, students had more options to choose from and thus they diversified. Students who were not successful in our school could try others and, if they proved to be more welcoming, that could create a reinforcing opinion that in the long run has led to the decline in student attraction in our school As Moller-Wong [MollerWong, 1997] points out, engineering schools should deal not only with attraction of new students, but also, and mainly, with the retention of students who already are enrolled. This lesson should be kept in mind in order to perform a successful assessment and put a remedy to the performance of our studies. We are backed by our results to state that students within cohorts that were exposed to teaching innovation performed better, 
and the overall attrition rate descended even if the pool of students' quality has been decreasing.

Therefore, the most important lesson is that the learning process matters, and it can account for a big proportion. Policies to attract students usually require big funding to promote advertising campaigns, visits to high schools, the organization of events, etc. When the school has to deal with these issues, it is entering a field that it is not used to. Overall universities are and should be teaching institutions more than advertisers or student hunters. We must require students to comply with certain requisites, but teachers themselves should pay back adapting their requirements to the pool of students they are facing and putting into practice the best teaching techniques to increase the learning process.

Our model has some useful features that make it possible to replicate this study. First it only needs data that can be gathered when the students start their studies in our school. Second, even if our results do not purport to be all-encompassing, as outlined above, the ultimate objective is to ensure that appropriate preventive measures are implemented so that we can both avoid early failure and we can increase student performance. Thus, by changing the focus of our techniques from predicting an outcome to mark a before invisible population in risk of attrition, we provide extra tools to policy makers for attacking early drop out before it is produced without adding costly expenditures. Third, this model is not closed and it could be expanded with further works and compiling additional data from students (like social environment, motivation, class climate) to make it more accurate.

In conclusion, we have presented evidence that data can lead to wrong conclusions if we don't attend to possible lurking variables. The performance is a function of the student potential and they way she is taught. Even if the potential accounts for most of the results (being this potential at the same time a function of the social class of the student, theme that deserves a specific article), there is still room to improve via teaching quality. That way, we could realize that the best policy to increase the number of students is not attracting new ones, but making sure that the nearly 30\% that has been lost in the first year remains and transmits the goodness of our studies. 


\section{Referencias Bibliográficas}

Becker, S. B. (2010). Why don't young people want to become engineers? Rational reasons for disappointing decisions. European Journal of Engineering Education, 35(4), 349-366.

Bernold, L.E., Spurlin, J.E., \& Anson, C.M. (2007). Understanding Our Students: A Longitudinal-Study of Success and Failure in Engineering With Implications for Increased Retention. Journal of Engineering Education, 96(3), p263-274.

Bonwell, C. C., \& Eison, J. A. (1991). Active learning: Creating excitement in the classroom. Washington, DC: School of Education and Human Development, George Washington University.

Felder, R. M., Felder, G. N., \& Dietz, E. J. (1998). A Longitudinal Study of Engineering Student Performance and Retention. V. Comparisons with Traditionally-Taught Students. Journal of Engineering Education, 87(4), 469-480.

French, B. F., Immekus, J. C., \& Oakes, W. C. (2005). An examination of indicators of engineering students' success and persistence. Journal of Engineering Education, 94(4), 419-425.

Hu, S., Kuh, G. D. \& Li, S. (2008). The Effects of Engagement in Inquiry-Oriented Activities on Student Learning and Personal Development. Innovative Higher education, 33(2), 71-81.

Knight, D. W., Carlson, L. E., \& Sullivan, J. (2007). Improving engineering student retention through hands-on, team based, first-year design projects. InProceedings of the International Conference on Research in Engineering Education.

Mills, J. E., \& Treagust, D. F. (2003). Engineering education-Is problem-based or project-based learning the answer? Australasian Journal of Engineering Education, 3, 2-16.

Moller-Wong, C., \& Eide, A. (1997). ). An engineering student retention study. Journal of Engineering Education, , 86(1), 7-15. 
Prince, M. (2004). Does active learning work? A review of the research. Journal of engineering education, 93(3), 223-231.

Suresh, R. (2006). The relationship between barrier courses and persistence in engineering. Journal of College Student Retention: Research, Theory and Practice, 8(2), 215-239.

Tyson, W. (2011). Modeling Engineering Degree Attainment Using High School and College Physics and Calculus Coursetaking and Achievement. Journal of Engineering Education, 10o(4), 760-777.

Takahira, S., Goodings, D. J., \& Byrnes, J. P. (1998). Retention and performance of male and female engineering students: An examination of academic and environmental variables. Título de la Revista, Journal of Engineering Education, 87(3), 297-304.

Winckler, G. \& Fieder, M., (2006). Declining demand among students for science and engineering?. Universities and business: Partnering for the knowledge society. London: Economica, 233-241. 
Table 1: Performance and details across cohorts.

\begin{tabular}{|c|c|c|c|c|c|c|}
\hline Cohort & $\mathbf{N}$ & $\begin{array}{l}\text { Mean grade } \\
\text { (Std.deviation) }\end{array}$ & $\begin{array}{lr}\text { Students } & \text { who } \\
\text { passed } & \text { all } \\
\text { subjects } & \end{array}$ & $\begin{array}{l}\text { Students who did } \\
\text { not pass any } \\
\text { subject }^{2}\end{array}$ & $\begin{array}{l}\text { Students } \\
\text { who passed } \\
\text { at least one subject² }\end{array}$ & $\begin{array}{l}\text { Mean } \\
\text { Performance students } 3 \\
\text { (Std.deviation) }\end{array}$ \\
\hline 2000-01 & 382 & $\begin{array}{l}7,099 \\
(0.569)\end{array}$ & $8.8 \%$ & $7 \%$ & 93.0\% & $\begin{array}{l}25,057 \\
(18.560)\end{array}$ \\
\hline 2001-02 & 396 & $\begin{array}{l}7,076 \\
(0.587)\end{array}$ & $7.4 \%$ & $11.2 \%$ & $88.8 \%$ & $\begin{array}{l}21,174 \\
(17.886)\end{array}$ \\
\hline 2002-03 & 379 & $\begin{array}{l}6,578 \\
(0.783)\end{array}$ & $3.9 \%$ & $19.3 \%$ & $80.7 \%$ & $\begin{array}{l}16,072 \\
(17.539)\end{array}$ \\
\hline 2003-04 & 367 & $\begin{array}{l}6.244 \\
(0.813)\end{array}$ & $4.9 \%$ & $16.9 \%$ & $83.1 \%$ & $\begin{array}{l}15.620 \\
(17.881)\end{array}$ \\
\hline 2004-05 & 288 & $\begin{array}{l}6.016 \\
(0.763)\end{array}$ & $1 \%$ & $35.7 \%$ & $64.3 \%$ & $\begin{array}{l}9.420 \\
(13.946)\end{array}$ \\
\hline 2005-06 & 197 & $\begin{array}{l}6.142 \\
(0.971)\end{array}$ & $11 \%$ & $35.8 \%$ & $64.2 \%$ & $\begin{array}{l}15.704 \\
(21.061)\end{array}$ \\
\hline 2006-07 & 144 & $\begin{array}{l}6.294 \\
(0.998)\end{array}$ & $8.7 \%$ & $9.8 \%$ & $90.2 \%$ & $\begin{array}{l}31.365 \\
(24.687)\end{array}$ \\
\hline 2007-08 & 153 & $\begin{array}{l}6.259 \\
(0.898)\end{array}$ & $11.2 \%$ & $8.5 \%$ & $91.5 \%$ & $\begin{array}{l}29.920 \\
(24.896)\end{array}$ \\
\hline Total & 2306 & $\begin{array}{l}6.551 \\
(0.870)\end{array}$ & $7.11 \%$ & $17.6 \%$ & $82.4 \%$ & $\begin{array}{l}19.444 \\
(19.891)\end{array}$ \\
\hline
\end{tabular}

1) High school average grades depending on the cohort (o-10 scale) 2) during the first year 3) Results according to the measure described in the text. 


\section{Table2: Influence of innovative teaching}

\begin{tabular}{|l|l|l|l|l|}
\hline & $\begin{array}{l}\text { Coefficient } \\
\text { (CI 95\%) }\end{array}$ & Std error & T-statistic & P-value \\
\hline High school grade & $\begin{array}{l}13.71 \\
(12.47-48.92)\end{array}$ & 0.40 & -13.56 & 0.000 \\
\hline Age & $\begin{array}{l}-0.33 \\
(-0.64---0.02)\end{array}$ & 0.16 & -2.09 & 0.037 \\
\hline Average classmate & $\begin{array}{l}-0.08 \\
(-0.12---0.47)\end{array}$ & 0.02 & -4.47 & 0.000 \\
\hline ITT & $\begin{array}{l}13.21 \\
(10.53-15.90)\end{array}$ & 1.37 & 9.64 & 0.000 \\
\hline
\end{tabular}

ITT: innovative teaching techniques. $\mathrm{R}^{2}=0.389$ 